\title{
THE DIGITAL DIVIDE AND HIGHER EDUCATION CHALLENGE WITH EMERGENCY ONLINE LEARNING: ANALYSIS OF TWEETS IN THE WAKE OF THE COVID-19 LOCKDOWN
}

\author{
Caroline M. AZIONYA \\ ORCID: 0000-0003-1051-274X \\ Faculty of Humanities \\ University of Johannesburg \\ Johannesburg, SOUTH AFRICA \\ Dr. Abyshey NHEDZI \\ ORCID: 0000-0002-2438-2686 \\ Vega School of Brand Leadership \\ Independent Institute of Education \\ Johannesburg, SOUTH AFRICA
}

Received: 10/11/2020 Accepted: 15/02/2021

\begin{abstract}
While literature reveals the positive perception of online learning, this study examines the issues caused by the digital divide for students at South African universities during the 2020 academic year. The study reveals the perceptions and experiences of university students from historically marginalised and privileged universities. This research ventures into relatively unexplored territory by examining the digital divide in the wake of the COVID-19 pandemic and radical shift to online learning. Using netnography, 678 tweets were analysed using qualitative content analysis and the concept of "digital divide," "online learning" and "student voice." We argue that digital media in the digital divide suffuses socio-economic relationships between university students and management. The study provides insights into the role of 4IR, the technological, digital inequalities, environmental, situational and institutional barriers/disparities students faced during remote learning and assessment. Results reveal, online learning did not increase the accessibility of university education during the pandemic for students attending marginalised universities. Network coverage, device type, time of day, socio-economic status and digital competence negatively affect synchronous lecture participation and attendance. More inclusive and flexible pedagogy based on a university's resources and student profile is needed to mitigate digital and educational inequalities affecting students from rural and/ low-income households.
\end{abstract}

Keywords: Digital divides, online learning, remote learning, higher education, COVID-19 pandemic.

\section{INTRODUCTION}

The academic year of 2020 saw a global outbreak of a new highly infectious disease, COVID-19 disrupting the world population, reshaping people's lives and higher education delivery conventions. The South African government declared a national state of disaster under Section 27(1) and Section 27(2) of the Disaster Management Act on 15 March 2020 - in response to the Covid-19 pandemic. Although online learning in higher education was mainly the result of the fast-paced developments in ICT for the ever-evolving digital economy (Palvia et al., 2018), the COVID-19 related lockdown restrictions radically forced the shift to online learning. COVID-19 forced higher education institutions (HEIs) in South Africa to weigh health recommendations against the needs of students, many of whom are casualties of the digital divide separating those who have unfettered Internet access and those who do not. A growing measure of discontent with the process of swiftly converting to online delivery at HEI's during the coronavirus pandemic and subsequent 
lockdown was met with tremendous criticism from marginalized students, concerned academicians and citizens. Mainly due to concerns that marginalized student's diminished access to devices and data and socioeconmic status created significant barriers to the remedial intent of emergency online teaching. Therefore it accentuated the pre-existing digital divides experienced by students.

\section{LITERATURE REVIEW}

\section{The Digital Divide}

As the most unequal society globally, South Africa's pre-existing digital divides are further accentuated by its income and wealth inequalities (Czerniewicz et al., 2020) which in turn affect marginalized students' digtal proficiency as they struggle to access and/or adapt to technologocal developments. Previous research into the inequalities arising from the emergence of digital technologies has incorporated socioeconomic factors, especially gender, age, race educational level, income, and habitat (Hasan \& Bao, 2020, Czerniewicz et al., 2020). Soomro, Kale, Curtis, Akcaoglu and Bernstein (2020 p.1) suggest the "digital divide centres on access to various dimensions of information and communication technology (ICT) including physical access, motivation, skills, and actual usage of digital technologies." While other researchers' conceptualisation of the "digital divide" focus on the lack of equity in the access and use of ICTs (Hidalgo, Gabaly, Morales-Alonso \& Urueña, 2020). The divide also refers to the gap between the "haves" and the "have-nots" in terms of access to online learning and resources for education purposes. Therefore, access and inequity are central concepts to this complex construct. Associated inequities can come in the form of

1. unequal access to technologies (first-level digital divide);

2. unequal development of the relevant skills needed to navigate the Internet as well as information literacy skills to seek and evaluate information (second-level digital divide) and;

3. the disparate benefits of technology usage according to socioeconomic status (third-level digital divide) (Lombana-Bermudez, Cortesi, Fieseler, Gasser, Hasse, Newlands \& Wu, 2020 p.11). Usage skills involves the frequency, duration of time, and types of activities performed.

Despite a growing number of studies into technological adoption within teaching and learning at South African HEIs in the wake of COVID-19 lockdown restrictions (Mhlanga \& Moloi, 2020), there is a need for studies that explicitly consider the technology and assessment utilisation of students in this emerging context. Previous studies have identified the lack of digital infrastructure, affordability and skills as the primary digital divide challenges in emerging economies (Duffy \& Ney, 2015). Numerous studies focus on academics' perspectives of technology and assessment, including a critical emphasis on the instructors' voice within digital technology use (Dwivedi et al., 2020). A few studies investigate issues critical to the student's experience of the digital divide with even fewer during a crisis. A need for student centred perspectives is needed to identify specific challenges, readiness and circumstances arising from the digital divide in times of crisis. Our research utilises Twitter data to assess this issue.

The paper is organised as follows. First, we discuss COVID-19's impact on HEIs in an emerging context. Specifically, online learning challenges, blended and hybrid models, Generation $\mathrm{Z}$ and the youngest Millennial student's learning dynamics, their digital literacy and the existing digital divides exposed during the pandemic. Following this, we will explain the methodology, then present and discuss the findings.

\section{Online Learning Challenges}

Higher education is celebrated as a vehicle for economic success but concerns about unequal access to new technologies, integrated within the concept of digital divide, has been a topic of study since the use of the Internet began to be prevalent among the population (Hidalgo et al, 2020). Literature shows learning that is facilitated by electronic technologies (known as online, distance, or e-learning), can be either fully online, mixed modes (known as hybrid or blended), or web assisted (Reilly, Gallagher-Lepak \& Killion, 2017). Gloria and Uttal (2020) define a fully online course as electronic or e-learning in a virtual computer learning space using a technological approach that allows students to learn without being in the same classroom as the instructor. Also known as distance or "remote learning" through the use of technology, the online classroom 
can occur as either a synchronous (where the teaching takes place live online) or asynchronous process and creates greater flexibility in where and when students learn (Lee, 2017). Blended classes use face-to-face teaching and technology-mediated channels to enhance interactive, engaging learning experiences and to improve student-learning outcomes (Auster, 2016). Blended course design, hybrid or mixed modality course design and flipping the classroom all describe the same approach. Although, online education is touted as a 'revolutionary' solution to diverse educational problems of inequality (Lee, 2017) key barriers were identified during the lockdown.

\section{Digital Disparities during the Covid-19 Lockdown}

Beaunoyer, Dupere and Guitton (2020) investigated digital disparities during COVID-19 periods. While most educational institutes are adopting online classes (Yen, 2020; Zhou, Wu, Zhou \& Li, 2020), the question arises - how this approach benefits students from low-income household and remote areas? Due to digital inequalities and lack of access to current technology, students from lower-income families have limited or no access to online classes. At the same time, excessive data costs present an obstacle to access online-classes (Adam, Kaye \& Haßler, 2020). In light of this, academics question the rationale of making use of sophisticated technology when students stand to be "disadvantaged" by it. They argue that converting a face-to-face course into a blended or online format is not a simple matter of moving ideas onto an online learning management system (Gloria \& Uttal, 2020:139). The different ways a student receives study material and the relationship between the lecturer and student need consideration. Worley and Tesdell (2009) argue that online courses require instructors to ask both pedagogical and technological questions that address the following. The most effective ways to facilitate student learning in online environments without the person-to-person immediate interactions of a classroom and finding ways to stay up-to-date with emerging online teaching technologies that offer students the best online learning options and the optimal coursemanagement system to adopt (Worley \& Tesdell, 2009). Perhaps, blended and hybrid models are better suited to address the challenges presented by the three categories of the digital divide mentioned earlier.

\section{The Digital Literacy and Curriculum Delivery for Generation Z}

Generation $\mathrm{Z}$ or Gen Z, are the cohort of people born after the millennial generation. Generation $\mathrm{Z}$ are currently undergraduate students at HEIs. Literature touts Gen $\mathrm{Z}$ as more adept in the digital, visual, and global realms than previous generations (Mosca, Curtis \& Savoth, 2019). Mosca, Curtis and Savoth (2019) describe its members as having never known life without the internet. In the South African context this is probably the case for the haves more than for the have nots. Universities from developed contexts, are changing pedagogy on the premise that Gen Z, live a big part of their social lives via texting and social media, where technology has blurred the lines of studying, entertainment, their private and public life. Responding to Generation Z's significant online content consumption, such universities are diversifying their course delivery platforms, including fully online, blended learning, and face-to-face courses (Yu \& Canton, 2020). However, the digital divide and educational inequalities remain a significant societal problem in South Africa's emerging context, affecting disadvantaged students from low income households. Accordingly, universities are challenged to meet the needs of students with varying levels of technological readiness with deficiencies in information and digital literacy shown to be a hindrance to student success (Takavarasha, Cilliers \& Chinyamurindi, 2018).

Digital literacy refers to the capability to comprehend and use information in several formats from a wide range of sources when it is presented via computers. The concept of literacy is not only limited to simply being able to read; it has always meant the ability to read with meaning, and to understand. Digital literacy or digital competence (i.e. information literacy, ICT skills, and technological literacy) is part of the competencies for lifelong learning (Martínez-Bravo, Sadaba-Chalezquer \& Serrano-Puche, 2020). Evolving digital divides in information literacy manifest with students who struggle to use digital tools (Reedy \& Parker, 2018). Digital tools are the devices, gadgets and various software and hardware artefacts that influence one's ability to learn how to use digital platforms for engaging in social, business and educational activities in a responsible and safe manner (Takavarasha et al., 2018). Historically Black universities were marginalised prior to South 
Africa's transition to democracy in 1994 and still have legacy issues that hinder their delivery. We refer to them as marginalised universities and their historically white and resourced counterparts privileged universities. Marginalised universities serve the majority of Black African and previously disadvantaged university students (Mzangwa, 2019). For marginalised universities, not only is technology access and device ownership less prevalent than at privileged institutions, but students are less prepared to use the internet, core computer applications, and digital library/scholarly resources for academic pursuits (Takavarasha et al., 2018). Kajee and Balfour (2011) highlight that in South Africa, an advantaged elite minority have multiple access routes to digital literacy in their sociocultural environments.

\section{The Digital Divides amongst University Students}

A less privileged majority still come from under resourced sociocultural backgrounds where digital technology is rare, and access is unevenly distributed (Kajee \& Balfour, 2011). Due to the COVID-19 lockdown, universities transitioned to emergency online learning even though not all students have easy access to Wi-Fi off campus. This became an issue when public universities asked students to move out of student residences and closed their campuses. Closing universities and taking students and educators out of face-to-face lecuture interactions is a pedagogical transformation that requires rapid mobilization across all university staff and resources for what scholars describe as emergency remote education (ERE; Bozkurt et al., 2020), emergency remote teaching and learning (ERTL; Czerniewicz et al.,2020), or re-engineered distance education (Bozkurt \& Sharma, 2020). This is in contrast to experiences that are planned from the beginning and designed to be online, emergency remote teaching (ERT) is a temporary shift of instructional delivery to an alternate delivery mode due to crisis circumstances (Hodges, Moore, Lockee, Trust $\&$ Bond, 2020).

Based on a review of relevant higher education scholarship, the authors grappled with the tensions that arise when educators harness digital technology for student learning, meet marketplace needs, and improve livelihoods during a pandemic. Marginalised university students, from the historically disadvantaged poor economic backgrounds, acutely experience digital divides and evolving inequalities (Mzangwa, 2019; Takavarasha et al., 2018). Drawing upon the data captured on Twitter's microblogging social media platform, the present qualitative study explores students' user generated content regarding online learning. It further explores, their thinking when assessing the attitudes of various South African universities, their beliefs and behaviours related to online learning during the COVID-19 related lockdown and why different university management are unable to provide a shared response to student's demand of inclusion concerning online learning. The challenges include the disruption of the academic calendar, the redesigning of assessment standards and access to digital tools.

Main research objective: To explore the sentiments expressed on Twitter by South African University Students during the COVID-19 lockdown about the rapid migration to remote/online learning for the 2020 academic year.

Secondary research objective:

- To explore how the digital divide affects students from resourced and marginalised universities

- The students' perceptions of the modes of teaching and learning remotely

\section{RESEARCH QUESTIONS}

We ask the following research questions:

- What are the challenges faced by university students during the rapid shift to emergency online learning during the COVID-19 lockdown?

- What are the disparities faced by university students during the rapid shift to emergency online learning during the COVID-19 lockdown? 


\section{METHODOLOGY}

\section{Background}

On March 15 2020, the University of Johannesburg (UJ) closed until further notice and all graduations were postponed. Students were asked to leave UJ residential facilities. After the government mandated lockdown was extended, HEIs had to embark on a radical shift to online learning.

A month after, accessibility to online learning began to trend on social media perhaps because of its sensational nature, and even attracted the attention of other South African university students from across South Africa. These included the University of the Western Cape, University of Pretoria, Univerity of Kwazulu Natal, Univerisity of Witwetesrand, and Walter Sisulu University. UJ management pledged their assistance to disadvantaged students. On the eve of the second term commencing at UJ, the negative sentiment that had dominated the hashtag which attracted news media's attention was quelled and UJ students resumed their academic studies. However, students from the University of Fort Hare (UFH) were battling to receive resources, support and media attention. In consequence, UFH management was not able to supress the issues raised by their students and by the time we stopped data collection the \#UFHNEEDSHELP hashtag was ongoing. These juxtaposing scenarios provided the inspiration for our methods and the motivation for this paper.

\section{Data Collection and Participants}

Data was collected from Twitter between 29 June 2020 and 31 July 2020. Students started the \#BoycottOnlineLearningUJ hashtag on April 16, 2020 in protest to UJ's announcement to use remote learning. On 2 June 2020, students from UFH started trending with the \#UFHNEEDSHELP, \#RescueUFH and \#SaveUFHAcademicYear hashtags. For the purpose of data collection, Twitter's search interface (https://twitter.com/searchhome) was queried using the words, phrases and hashtags such as remote learning, \#BoycottOnlineLearningUJ, \#NothingForStudentsWithoutStudents, \#UFHNeedsHelp and "\#boycottonlinelearning. The tweets collected for this enquiry are demonstrative rather than representative. Meta-data such as number of retweets, replies, and date of contribution were also collected. We downloaded the data, we each went through the data, we grouped the similar tweets based on emerging themes and we then used excel to breakdown of themes.

\section{Sample, Coding and Analysis}

Six hundred and seventy-eight tweets were collected and 20 irrelevant tweets were eliminated. Although the majority of tweets for both hashtags were posted by different students, there were a few examples of students that were posting more in comparison with other users, particlualry at UFH. The remaining 658 tweets were analysed. The volume of tweets relates favourably with previous studies that involved manual coding (Aharony, 2012). Data were first analysed using Atlas ti. software, and exported to an Exel spreadsheet and Microsoft Word for additional coding and further analysis using qualitative content analysis. We used an inductive approach to condence the tweets. Specifically, the analytic induction process involved both researchers who interpreted 658 tweets vigilantly and assigned them to relevant categories. Using Exel, we were able to identify categoriesbased on similarities in tweets. Agreement on the labels were achieved through the repetitive coding of the tweets. Content analysis is a reputable and widely applied tool for previous studies, including higher education research (Kebritchi, Lipschuetz \& Santiague, 2017). Duplicate tweets were identified and the second tweet was not counted.

We adhered to recommendations set out by Christensen and Larsen (2020) regarding the collection, analysis and presentation of Twitter data. No ethical approval was required as all data (tweets) were retrieved from the public domain and would not constitute an ethical dilemma in internet research. However, all tweets were anonymised with metadata and tweet content were stored separately for ethical considerations. We did not include any tweets that constituted hate or libellous speech. For ethical considerations in internet research, the data collection process entailed removing personal identity data for all tweets collected from Twitter (Ahmed, Bath \& Demartini 2017). Although quoting a tweet ultimately identifies the source even when the 
names of participants are anonymised, an effort was made to create some confidentiality by de-identifying participants. Anonymity is applied in order to avoid harm including judgements and/or potential ridicule (Ahmed et al, 2017) we used quotes with no handles/usernames (Beninger, Fry, Jago, Lepps, Nass, \& Silvester, 2014) and no photos. Although Twitter data is a rich data source that provides insights into peoples' genuine opinions, it has its limitations. Twitter data is not representative of the general public (Blank, 2017). It is based on self-selection on several levels, in our case data is only collected from people who have internet access, who have a Twitter account and who decided to contribute to the respective hashtag thread..

\section{RESULTS AND DISCUSSION}

To our knowledge, this study is the first to analyse the usage of Twitter by students, activists and sympathisers in response to remote learning or online during COVID-19 lockdown restrictions in South Africa. Tweets were categorized into five major topical themes. Themes highlighted issues related to: (1) The inevitability of the fourth industrial revolution (4IR), (2) digital inequalities and technological barriers to online learning for students, (3) environmental and situational barriers for students, (4) challenges with online teaching and learning (5) historical and institutional barriers/disparities.

\section{Theme 1: The Fourth Industrial Revolution is Inevitable}

The first striking theme to emerge from analysis is the notion of 4IR as inevitable in the context of lockdown. Davis (2016, p.11) describes 4IR as "the advent of cyber-physical systems involving entirely new capabilities for people and machines." Unlike the third industrial revolution, 4IR takes technological advancement to new levels. "The fusion of technologies is blurring the lines between the physical, digital, and biological worlds" (Davis 2016, p.11). This concurs with the general view around the increased digitalisation of work(places), new "types" of students will emerge who may be more digitally competent than previous generations due to their "digital native" status (Gillett-Swan, 2017). For this to happen, students would need to come to university with the digital literacy, access and usage skills to participate in 4IR mediated learning environments. However, the literature paints a picture of persistent divides. Participants who posted about the inevitability of 4IR emphasize the compelling evidence of the disruptive capability of the technology driven transformations of business and human activities (Oke \& Fernandes, 2020), and in the teaching and learning context (Radha, Mahalakshmi, Kumar \& Saravanakumar, 2020). In highlighting the importance of technological advancement for learning one user tweeted:

We are approaching 4IR, therefore like you said, \#elearning is inevitable.

COVID-19 and the subsequent lockdowns around the world and reports in the media were a huge catalyst for the digital transformations of many sectors. Organisations and individuals had a new normal thrust upon them and used virtual spaces and digital tools for work, studying and leisure. In recognition of the emergence these sweeping changes they were witnessing, another user makes a subtle reference to inequality as the problem while accepting the importance of online learning.

Our problem is inequality not online learning. Online learning is inevitable. The best we can do is to help students with resources as we do with food parcels.

Literature suggested that students "from disadvantaged backgrounds need even more support and care than students from well-to-do backgrounds" (Guri-Rosenblit, 2009, p.11). In a sense this user, likens access to digital resources for students as a fundamental need such as food. Despite the necessity to prepare for emerging digital contexts by skilling, reskilling and upskilling marginalised students to participate in 4IR, one user cautions university management from using students as guinea pigs:

We can't allow the university to practice and test 4IR at the expense of student's academics. 
This statement also reveals students limited grasp of 4IR. Online teaching does not equate to 4IR, unless instruction heavily relies on 4IR technology. The drastic shift in teaching approaches employed during the lockdown raised questions in the minds of students about the quality control and reputation of the offering and the outcomes at universities as articulated by these users:

A rapid radical shift in the teaching and learning methodology without proper planning and revision of strategy will compromise the prestige and credibility of certain qualifications, students and the contact university community.

We cannot be subjected to online learning especially on a short notice.

Not only were students concerned about the quality of the offering but they perceived universities as subjecting them to the possibility of failure due to being ill prepared to meaningfully engage online either because they lacked temporal and material resources. Students expressed a distrust of the approach universities adopted and their impact on marginalised students. They were worried that no one had their interests at heart, as online learning is a resource intensive approach.

The way universities are going about it suggests that they are gambling with the degrees of the poor.

Specifically, students positioned online learning as a threat to throughput rates and increasing the possibility for academic exclusions because they believed it would require a steep learning curve:

Can the University of UJ please introduce e-learning once they can assure us that no student will be left out, no one will be academically excluded and everyone has access to ulink and Blackboard with a proper functioning device.

I don't think we are in a position to successfully roll it (online learning) out now considering the many facets of our society.

Differences in capabilities were noted amongst different categories of institutions.

Predominantly white universities will succeed in their migration to online learning, but what about Black universities and colleges?

Despite these misgivings, students recognised the need to save the 2020 academic year and the best strategy to achieve this.

E-learning is the only apparent solution to save the 2020 academic year.

However, others advocated for a blended learning versus fully online approach to address the issues of preparedness of students and institutions as advocated by this user:

... Going forward, it (online) needs to be used hand in hand with contact learning.

This indicates that students were not entirely resistant to online instruction but took issue with the speed with which it was introduced. They probably would have accepted it more readily using a blended approach. 
Although it was not possible during the lockdown, educators should recognize the need for hybrid approaches to address the needs of a diverse student profile (Auster, 2016). Despite being branded netizens, it seems South African Generation Zs prize face to face instruction over computer mediated approaches. Therefore, to successfully promote online learning, universities should not substitute traditional face-to-face instruction with online learning methods, but rather use a combination (Takalani, 2008).

\section{Theme 2: Digital Inequalities and Technological Barriers to Online Learning for Students}

The second theme highlights the lack of hardware, concerns of access to Wi-Fi, network challenges students faced and the cost of data for online learning during lockdown.

\section{Disadvantaged Student's Lack of Devices}

The following tweets highlight the device challenges faced by the most marginalised students before the lockdown. Either such students lacked devises or their devices had limited functionality.

My homie uses those R150.00 (+/-\$8) phones (feature phone with a small screen) and doesn't have laptop. I wonder how he will be able to access online learning, he relies on me even for him what's happening at VUT via social networks.

Other students don't even have smart phones/laptops to type assignments.

Undertaking online learning means being reliant upon network adapters, power, devices, servers, routers and software.

Material access is the commonly mentioned type of digital divide, involving the physical access to an internet connection, the costs for hardware, software, and service (Reilly et al., 2017). To mitigate the lack of devices for marginalised students, universities have computer labs equipped with printing facilities. Students also have access to free Wi-Fi on campus and university run residences. There are often long lines at the labs due to demand. Although smartphones afford students with better access than feature phones, they are not ideal for long assignments. During the lockdown, students had no access to these facilities.

\section{Network Coverage Challenges-Remote and Underserviced Areas}

Network challenges for students manifest as an urban rural divide. During the lockdown, remote learning was problematic for students based in rural areas due to infrastructure that online learning requires. As argued by Mhlanga and Moloi (2020) the rural areas are plagued with a number of challenges related to poor internet connectivity, and the poor state of infrastructure. Users noted the following about network coverage where they live:

The problem is some villages have no network.

An issue affecting both rural and urban dwellers that had access to a network, revolved around network speeds, bandwidth and the household demand. Note the number of users on the Wi-Fi router.

Pros and cons of internet speed in SA, when you put 5-10 users in one Wi-Fi router, we can't watch a single YouTube video at once. Buffering for ever.

This also gives an indication of the level of possible overcrowding at home. This issue is dealt with in more detail in theme three. 


\section{Prohibitive Data Costs}

The prohibitive costs of data for online learning was a common theme as evidenced by the following tweets

My brother is at UKZN, right now he's home! He won't be able to participate in this online learning thing because as much as he has a laptop, at home we won't afford to buy him that much data ...

Online classes, assignments, assessments and exams would require over a thousand gigabytes of data which students at home can hardly afford and not forgetting poor network coverages and learning materials left at respective reses.

Students whose household income is not low enough to satisfy criteria for government bursaries nor qualify for bank loans face the following dilemma.

The data is too expensive for missing middle students to keep up with their online studies every day.

To mitigate these costs, Mhlanga and Moloi (2020) explain that the government of South Africa went into partnership with mobile network operators (MNO) to offer zero-rated applications and educational websites. An application or website is defined as zero-rated when an MNO does not count the usage of the application or website against a user's monthly data allotment, which renders its use as effectively free (Mhlanga \& Moloi 2020). The main MNOs such as Vodacom, Cell C, and MTN, agreed. However, not all the platforms students used for learning are zero-rated and therefore require buying of data.

What's the point of making blackboard zero rated but lecturers still requesting us to submit assignments via emails?!

Although students have access to various journals, periodicals through their institutional library for the purposes of research, their preference for Google's search engine over their institutional repository is notable.

Also, UJ has made Ulink (Blackboard) free and while that is appreciated, Ulink doesn't have our study materials, it's not the site where classes happen, it's also not the site where we do research.

... Blackboard might be free ... but Google isn't.

\section{Theme 3: Environmental and Situational Barrier for Students}

The review of tweets revealed that issues related to environmental and situational barriers are summarized into students' home environment.

\section{Non-conducive Study Environment}

This theme relates to students affected by non-conducive study environments in their home environment. Particularly for students living in poverty and/or informal settlements. Informal settlements are characterised by poor living conditions that lack water and sanitation and sometimes electrification depending on the location and age of the settlement as evidenced in the images below. Users retweeted two images and noted:

... Some students are staying in environment that cannot be conductive for them to cope and study. 
Informal settlements are densely populated and often have many people sharing one room. They lack infrastructure and experience high levels of poverty, overcrowding, violent crimes such as robbery, genderbased violence and murder. The images paint a vivid picture of the specific challenges marginalized university students face during online learning. One user tweeted:

This is the place we call home so according to UJ we have a perfect data connection, peacefulness and it's ... conducive ... for us to catch up with studies daily and write exams.

Don't confuse staying here to get through high school (as) the same as staying here to get through varsity via online learning, because it's not the same.

As a poor student from the townships have been struggling with this online thing.

For students with disabilities, particularly those living in poverty, the barriers and marginalization were compounded by a lack of access to university support services.

There are so many physical disable(d) students at @go2uj who rely on the institutions' resources for learning. Currently, they do not have any access to such resources, such leaves them at a disadvantage to learn and move with this online learning.

\section{Environmental Distractions and Interruptions}

Students from different socio-economic circumstances complained about various distractions in their home environment. Interruptions and home responsibilities heightened the inability for affected students to fully participate in any live, scheduled contact. Many users complained about lacking a quiet place to study and participate in class. Commitments such as chores during live lectures also affected the attendance and participation of students. This user explains:

Online learning is effective currently. The problems we face at (our) homes hinders some of us living with parents who misunderstands. Our parents don't tolerate such, you'll be doing chores all day, we can't Even sleep or get any chance to write. *Stepmoms.

I also need to take care of my siblings, in the midst of this where do I get the chance to sit down and open a laptop and study? Meanwhile somewhere in Lovemore Heights or Sandton (affluent suburbia) there's John or Tracey who has wifi at home and goes to the study room to study.

The contextual challenges presented in this theme negatively contribute to the poor performance and participation of students during synchronous lectures and assessments. It is therefore important to examine student's experiences of online teaching and learning to help educators design better learning experiences that do not disadvantage students.

\section{Theme 4: Students Experiences with the Modes of Teaching and Learning}

The next theme deals with the challenges with synchronous lectures and assessments, and the technical challenges experienced by students. Students' readiness to attend online courses is one of the major issues discussed in tweets. Not all students can successfully participate in online courses. Adopting and accessing online teaching and learning, internet access required to participate in online courses can be challenging for students as highlighted in themes one to three. University educators must design their course delivery with students that have extraneous circumstance in mind. Specifically rolling out narrowly timed online education. 


\section{Synchronous Lectures}

Various pedagogical issues were raised around the timing of lectures. Synchronous teaching is data consuming and the poor connectivity challenges made it hard for students to attend live online sessions. Students expressed concern about lack of bandwidth for live video lectures regardless of the application being used (Blackboard Collaborate, Zoom or YouTube).

It's (an) inconvenience for students from rural areas,... other lecturers want to be live on YouTube.

Although Zoom is purported to be less data intensive than YouTube it still presented challenges for students with connectivity issues.

Students are told to attend classes on Zoom yet they stay in rural areas that have poor network connectivity.

Furthermore, students accessing live Blackboard Collaborate sessions using unstable Wi-Fi connections get kicked out when there is a break in the connection. Other users complained of being unable to connect at certain times of the day:

Zero rated gets congested midday, in the morning it works perfectly.

Therefore, an unreliable network and poor connectivity were among the challenges that make it difficult for students to join live lectures or sustain an uninterrupted connection for the duration of their lecture. Consequently, not all students can attend these sessions. The same is true for online assessments

\section{Synchronous Assessments}

Many students' expressed feelings of frustration and helplessness around submission criteria and/or requirements for assessments that disadvantages students.

If ... the connection becomes compromised ....(it) may result ...(in) ... failing a test.

We writing Test 1 online, we all know how Ulink works once you disconnect for a second ,your attempt submits a Boom here comes your fail.

Imagine living in an area where you have to turn flight mode on and off to get $4 \mathrm{G}$ coverage and then ... do your timed quizzes.

UJ: This exam can only be completed in one sitting. The exam will be available for 2 hours from 12:00 -14:00. Make sure you have a stable internet connection as the test allows only 1 attempt. MTN: your anytime data is finished. MTN: No internet connection.

Where am gonna write online test? Laptop. It's winter, load shedding for one etc.

When lockdown commenced, Eskom, a national electricity service provider, was conducting rolling blackouts nationally to stabilise the national power grid. This effectively meant that if a lecture, assessment or consultation was scheduled during such a period not all students could participate/complete an assessment. 
They would need enough battery life for their devices (laptops, mobile routers etc) or an alternate internet connection if they had fibre. As a result, students preferred the flexibility that asynchronous lectures and most probably for assessments, provided them with. One student stated:

I like this online learning thing because I attend class whenever I'm ready to.

One user lamented the frequency of assessments implying that some lecturers' substituted face to face lectures with over assessment.

When they said online learning, this is not what I had in mind. Everyday there is something due.

\section{Technical Difficulties Related Software and Applications}

Despite studies' acknowledgement of the benefits of online learning, technical issues can affect software functionality, user experience and lead to frustration. Building on theme three, other software related limitations to student lecture interactions and synchronous interactions were noted:

... Specific softwares such as Blackboard can slow down interaction and provide limits to functionality while also adding to the time limitations and frustrations experienced by both staff and students.

Students did not always seamless experiences using institutionally designated apps and platforms.

An institution (CPUT) with a server that crashes from time to time on busy days claims to be ready for online learning.

Blackboard and Blackboard Collaborate both have mobile apps designed for a mobile first student. The apps allow students to participate in online classes using a phone, tablet or laptop. However, some students experienced glitches that resulted in unplanned expenses.

After struggling to access material on the website I resorted to downloading the Blackboard App (using my data) and MORE challenges arose... we not complaining vainly...

Depending on the institution, students could download Office 365 to access Word, PowerPoint and Excel free of charge. However, the challenge revolved around if devices had the RAM to accommodate the software

....There are students who aren't privileged enough to have ... a laptop or phone that can run Microsoft Word?

Other challenges students faced during the lockdown were directly linked to the institutional capacity of the university they attend. Students needed support and services for the successful transition to online learning.

\section{Theme 5: Historical and Institutional Barriers/Disparities}

An emergent theme relates to institutional disparities for marginalised universities and privileged institutions. Historically white universities such as

...Wits, UJ and other privileged universities....

used their resources and infrastructure to address data and hardware inequalities highlighted in Theme 2 . 
To ensure inclusivity of all students' \#UJ secures $30 \mathrm{~GB}$ of data per student per month and a further distribution of 4000 laptops to qualifying students as part of the remote learning programme.

Wits is loaning (marginalised) student(s) computers and delivering them to their homes.

All universities should follow University of Pretoria to postpone online learning until they have ensured that all the academic support is guaranteed, and all resources have been made available. UP has postponed until the 5th of May.

In contrast, historically marginalised institutions were plagued with different challenges. The majority of black disadvantaged students come from mostly rural and underdeveloped provinces in the Eastern Cape, KwaZulu-Natal and Limpopo (Dube, 2020). Two of these provinces are home to marginalized universities. While so called privileged universities were focused on the logistics of online learning. Marginalised universities were focused on damage control. Students were not all registered for the 2020 academic year.

... Since the start of the academic year, Walter Sisulu University battled with admission and registration etc...

At University of Venda we still have students who haven't registered up to date. Not to mention that most of the students haven't received their allowances and are told they will receive after lockdown.

Institutional inequalities caused by inability to roll out quotas for students to return to campus timeously occurred in marginalised universities.

Other universities are done with 1st semester and now are in 2nd semester and Forte haven't done anything, some networks users haven't received their data, no catch-up plan, no laptops, some final year students haven't received their permits, no allowances.

\section{DISCUSSION OF FINDINGS}

\section{Digital Access Inequalities}

The study has revealed that students felt 4IR is inevitable. In the same vein Abdulrahim and Mabrouk (2020 p. 292) observed that COVID-19 accelerated transformations to 4IR that are influencing higher education and how HEIs are prepared to face particular challenges. From this research, it emerged that there were technological, pedagogical, and social challenges affecting the deployment of emergency remote online learning at marginalised universities. Despite COVID-19's abrupt disruption to teaching and learning, some students continued without significant interruptions because of online learning (Outhwaite, 2020). Previous studies confirm that many emergency remote educational approaches are dependant on internt access, data and devices for the continuation of teaching and learning (Bozkurt et al., 2020). During the university closures, existing inequalities connected to different socioeconomic situations have widened because of a lack of resources, including access to educational technology and the Internet, a lack of physical spaces to carry out home-based remote learning among students from poor backgrounds (Czerniewicz, 2020). South Africa's with its well documented inequalities, entered the COVID-19 crisis with numerous contributing factors that exacerbated the digital divide. These factors continue to widen this gap during the pandemic. Only two priveldeged universities finished their 2020 academic year on schedule. Our findings show what is described by Bozkurt et al (2020) that during this crisis, those who are privileged to have data, devices and digital literacy were able to shift to emergency remote education far better and those that do not have such affordances. This is similar to a Ghanean study which indicates that the majority of students struggle with access to the Internet and conducive learning environments (Owusu-Fordjour, Koomson \& Hanson, 2020). 


\section{Learning Environmental and Situational Barriers for Students}

Social factors were also reported to hinder emergency remote learning. Coman, Tiru, Mesesan-Schmitz, Stanciu and Bularca (2020 p.14) observe "environmental disruptors such as the noise made by family members or neighbours and the lack of adequate learning space also influence the amount of time for which students can concentrate while learning online." This study highlights student frustrations around ERT and the university and government mandated removal of their campus study space. Similar to our study Coman et al. (2020 p957) confirmed that "students and staff were thrust into a lack of dedicated space to work undisturbed and the need to care for family members and especially children who must be home-schooled during the lockdown. Students reported more family responsibilities like running errands, household chores." In contrast to our study, most studies indicate students have positive attitudes towards online learning (Burac, Fernandez, Cruz \& Cruz, 2019; Odit-Dookhan, 2018), despite sometimes encountering technical issues (Alsaaty, Carter, Abrahams \& Alshameri, 2016). Analogous to our study Coman et al. (2020) confirm that most students' preference for face-to-face instruction and blended and hybrid models that include contact with lecturers and peers in lecture halls. Furthermore, the negative response from marginalised university authorities and critics only lowers their motivation and increases students' frustration and the risk of dropping out (Coman et al., 2020). The digital divide in South Africa follows the growing inequality gap in the country (Bozkurt et al., 2020) making some students who live in overcrowded informal settlements and rural areas lack a conducive space for learning (Aboagye, Yawson \& Appiah, 2020).

\section{Pedagogy Experiences with Emergency Remote Online Learning}

Our findings indicate that resource inequalities affected pedagogical design especially at marginalised residential universities which were unfamiliar with remote online learning. Synchronous lectures were by in large not effective (Coman et al., 2020; Williamson, Eynon \& Potter 2020). Studies recommend that asynchronous activities might be more reasonable than synchronous ones. Flexibility with deadlines for assignments within courses, course policies, and institutional policies should be considered (Hodges et al., 2020). These findings confirm observations by Ramsetty and Adams (2020) who asserted that a combination of technology and in-person services has been found to help address some of this disparity, these certainly are not quick fixes, especially while in the midst of a pandemic. Others are to be aimed for in future and steadily worked toward rather than accept the current status quo (Ramsetty \& Adams, 2020). Mpungose (2020) further argues that students were confused about the resources available for e-learning and the practicalites of transitioning from face-to-face to e-learning. This was compounded by the unavailability of appropriate policy to guidie an e-learning policy and a lack of instructional designers at some HEIs to provide relevant capacity building for students (Mpungose, 2020).

\section{Disparities between Historical Disadvantaged and Historical Well Resourced Institutions}

As the world reels form the impact of COVID-19 pandemic, universities everywhere have faced enormous disruption as a result. With a disparity of resources, universities moved their teaching and learning online. This rapid shift has particular significance in the South African context, where stark disparities in Internet connectivity and infrastructure persist for historically disadvantaged universities. These divides, laid bare by COVID-19 (Priyadarshini \& Bhaumik, 2020), were a major obstacle in the drive for inclusive and equitable access to higher education since post 1994. This study observed that students were concerned that the universities' rapid shift to ERT was not inclusive. Based on an argument by Bhaumik (2020), there was widening disparities in access to education during COVID-19, a deepening crisis. Our study is also in line with other studies (Czerniewicz et al., 2020) which suggest that certain students within the higher education sector life chances were cruelly diminished because of resource inequalities. In line with our findings, authors expressed that the crisis has laid open the fault line that existed through the historical, geospatial, economic inequalities of the country (Czerniewicz et al., 2020). In order to move online, Czerniewicz et al. (2020) relate that institutions made plans to address inequalities on connectivity and devices drawing from their own finances, individual universities donated, loaned, or financed for students. However, these choices were uneven, because it relied on the institutions' budget affordances and actual devices provided (Czerniewicz et al., 2020). 


\section{CONCLUSION}

The study provides insights into university student's perspectives on the emergence of 4IR in education, and the technological and digital inequalities they faced while learning remotely during lockdown. It also elucidates the barriers and challenges students experienced during class and assessments because of their socioeconomic status, spatial context and the historical barriers/disparities of their university. Although the issues faced by marginalised and privileged institutions have some overlap, the extent to which they manifest is fundamentally different. To provide an equitable education for marginalised students, their lack of resources and that of marginalised universities must be acknowledged (Lee, 2017) by the government and direct the conceptualisation and implementation of appropriate remote learning policies and strategies for students to benefit. Online learning did not increase the accessibility of university education during the pandemic for students attending marginalised universities. Increasing the accessibility was, in fact, a complex and challenging process that revealed the digital divide among students and different universities.

\section{Recommendations for Remote Learning when Face to Face is not Possible}

Our findings demonstrate the failures of a one size fits all approach to remote learning. Teaching should consider the curriculum, the digital competencies (skills, devices and access) of students, if a module is applied, theoretical or clinical and the class size. Based on our teaching experiences during lockdown at a privileged university, to accommodate marginalised students we recommend the following. The use of PowerPoint Presentations with impactful visuals, case studies, narration and scripts where possible to be shared and engaged with asynchronously. Content must be saved in different formats (e.g. MP4, PowerPoint, Pdf) that can be further compressed into smaller file sizes and made available on different platforms (Blackboard, WhatsApp, Google Drives). Break up content into smaller episode/sessions (15-20 minutes). Synchronous sessions are for questions and clarification. Students can also use email, Blackboard Collaborate, Zoom or WhatsApp groups for the same purpose. Assessments should be used with a combination of short questions and essays that have a strong critical thinking versus testing route learning component. The settings for timed quizzes should consider unstable student connections and be available 24 hours to accommodate the home environment. Take assignments with a research component and submit via a plagiarism checker.

The provision of a multimodal approach in which course content is highly flexible and accessible through multiple media formats for students to choose what is conducive to their learning context. For example, in areas where there is no connectivity, or a university is unable to provide data and devices for all students, they can receive teaching and learning material through post-delivery. If some barriers cannot be addressed in the moment, IHE should have a campus-based 'second-opportunity.'

\section{Limitations and Further Studies}

Despite the novel contributions above, the study has some limitations. We analyzed the tweets with a qualitatively focused interpretative approach which is subjective, other researchers may have different insights. However, we had numerous discussions during our research process to ensure we agreed on the meanings interpreted from the data. We also make our analysis paths as visible as possible. Future studies could expand on these findings and look at management and educators' reaction to emergency online learning during the pandemic.

Future research directions could analyse students' perspectives, experiences, attitudes, and feelings and compare them with other African countries, in order to provide a more comprehensive view of the phenomenon and to attain more detailed results. Research can also focus on lecturer experiences and readiness during the first wave of COVID-19. Our study did not reflect the lecturers' performance and skill barriers during emergency online remote teaching, an opportunity for further studies. One of the limitations of this study is that it is a qualitative inquiry and application of quantitative and statistical analysis of these tweetscould yield more insight into specific characteristics of students that were affected by the digital divide and racial inequalities. Moreover, further studies could also consider a quantitative descriptive survey method to tests some of the findings emerging in this study which relate to historical disadvantaged versus historically privileged institutional disparities. A representative quantitative surveycould follow up on the study to establish how students' experiences may have an impact on drop out or resilience to emergency online remote teaching. 


\section{BIODATA and CONTACT ADDRESSES of AUTHORS}

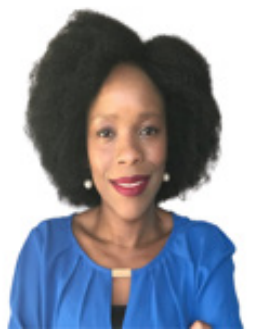

Caroline M. AZIONYA (MA.) is a lecturer of Strategic Communication at The School of Communication at the University of Johannesburg. Caroline is a Ph.D. candidate in the Department of Strategic Communication. Her academic interest areas include learning agility, digital multisided platforms, generation theory, and brand theory. Caroline has 4 articles, 3 book chapters, 3 industry reports, and 10 conference papers. She has written a thought leadership article submitted to a local newspaper.

Caroline M. AZIONYA

Department of Strategic Communication, Faculty of Humanities

Address: Cnr. Kingsway Avenue and University Road Auckland Park 2006, Johannesburg, South Africa Phone: +270115597889

E-mail: carolinea@uj.ac.za

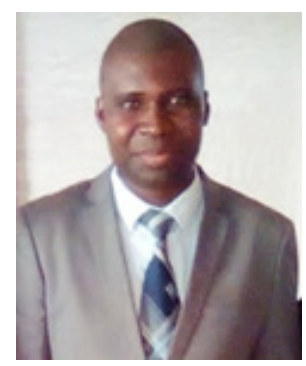

Abyshey NHEDZI (Ph.D.) is a Researcher Associate affiliated with the Vega School of Brand Leadership. Dr. Nhedzi gained his Ph.D. in Marketing Communication in the Department of Strategic Communication, the University of Johannesburg, in April 2016. His research interests include brand linkage, online education, blended learning, remote learning, digital media, marketing communication, and generational media use. Abyshey's research is three-fold in the fields of branding, media, and education. His research focuses on the conduction of pre-posttest experiments focusing on card scoring method and survey methodology. With teaching, he focuses on professional skills in the workplace. His industry-related research focuses on strategic communication as a whole, the practice, adaptation to 4IR, and this is in the context of higher education learning. He has over 8 journal articles published in national and international articles, 7 local conference papers, and 2 papers submitted to the international conferences. He is a seasoned Communication Journal reviewer.

\section{Abyshey NHEDZI}

The Vega School of Brand Leadership, The Independent Institute of Education (IIE-Vega)

Address: IIE-Vega, 444 Jan Smuts Ave, 2006, Johannesburg, South Africa.

Phone: +270115597889

E-mail: abyshey1@gmail.com

\section{REFERENCES}

Abdulrahim, H. \& Mabrouk, F. (2020). COVID-19 and the Digital Transformation of Saudi Higher Education. Asian Journal of Distance Education, 15(1), 291-306.

Adam, T., Kaye, T., \& Haßler, B. (2020). The Maldives and Sri Lanka: Question and Answer Session. (EdTech Hub Helpdesk Response No 18) DOI: 10.5281/zenodo. 3885817. Available under Creative Commons Attribution 4.0 International.

Ahmed, W., Bath, P., \& G. Demartini, 2017. Chapter 4 Using Twitter as a Data Source: An Overview of Ethical, Legal, and Methodological Challenges. In: Woodfield, K., (ed.) The Ethics of Online Research. Advances in Research Ethics and Integrity, (2). Emerald, pp. 79-107. ISBN 978-1-78714-486-6.

Aharony, N. (2012). Twitter use by three political leaders: an exploratory analysis. Online Information Review, 36(4), 587-603. doi:10.1108/14684521211254086

Alsaaty, F.M., Carter, E., Abrahams, D., \& Alshameri, F. (2016). Traditional Versus Online Learning in Institutions of Higher Education: Minority Business Students' Perceptions. Business and Management Research 5 (2), 31-41. 
Auster, C.J. (2016). Blended Learning as a Potentially Winning Combination of Face-to-face and Online Learning: An Exploratory. Study Teaching Sociology, 44(1), 39-48.

Bhaumik, R. (2020). Widening disparities in educational access during COVID-19: A deepening crisis. In Naumovska, L. (ed.). The impact of COVID19 on the international education system. IGNOU, New Delhi, India. DOI: https://doi.org/10.51432/978-1-8381524-0-6_10

Beaunoyer, E., Dupere, S., \& Guitton, M.J. (2020). COVID-19 and digital inequalities: Reciprocal impacts and mitigation strategies. Computers in Human Behavior, 111, 111, 106424.https://doi. org/10.1016/j.chb.2020.

Beninger, A. K., Fry, A., Jago, N., Lepps, H., Nass, L., and H. Silvester. 2014. Research using social media; users views. Natcen social research. http://www.natcen.ac.uk/media/282288/p0639-research-usingsocial-media-report-final190214.pdflnhttp://www.natcen.ac.uk.(Accessed 27 November 2020).

Blank, G. (2017). The Digital Divide Among Twitter Users and Its Implications for. Social Research. Social Science Computer Review, 35(6), 679-697.

Bozkurt, A., Jung, I., Xiao, J., Vladimirschi, V., Schuwer, R., Egorov, G., Lambert, S.R.... Paskevicius, M., + (2020). A global outlook to the interruption of education due to COVID-19 Pandemic: Navigating in a time of uncertainty and crisis. Asian Journal of Distance Education, 15 (1) 1-126. 10.5281 /zenodo. 3878572 .

Bozkurt, A., \& Sharma, R.C. (2020). Emergency remote teaching in a time of global crisis due to CoronaVirus pandemic. Asian Journal of Distance Education, 15(1), i-vi. https://doi.org/10.5281/zenodo.3778083

Burac, M.A.P., Fernandez, J.M., Cruz, M.M.A., \& Cruz, J.D. (2019). Assessing the impact of e-learning system of higher education institution's instructors and students. IOP Conference Series Materials Science and Engineering 482, 1-8.

Christensen, L.L., \& Larsen, M.C. (2020). Ethical challenges in digital research: A guide to discuss ethical issues in digital research (2nd ed.). Aalborg Universitet, Digetik, DigHumLab. https://dighumlab. org/wp-content/uploads/2018/10/Ethical_challenges_in_digital-research.pdf

Coman, C., Țiru, L.G., Mesesan-Schmitz, L., Stanciu, C., \& Bularca, M.C. (2020). Online Teaching and Learning in Higher Education during the Coronavirus Pandemic: Students' Perspective Sustainability; Basel 12, (24) 10367. DOI:10.3390/su122410367

Czerniewicz, L. (2020). What we learnt from "going online" during university shutdowns in South Africa. Retrieved January 26, 2020 from https://philonedtech.com/what-we-learnt-from-going-onlineduring-university-shutdowns-in-south-africa/

Czerniewicz, L., Agherdien., N., Badenhorst, J., Belluigi, D., Chambers, T., Chili, M., de Villiers, M., Felix, A., Gachago, D., Gokhale, C., Ivala, E., Kramm, N., Madiba, M., Mistri, G., Mgqwashu, E., Pallitt, N., Prinsloo, P., Solomon, K., Strydom, S., Swanepoel, M., Waghid, F., \& Wissing, G. (2020). A Wake-Up Call: Equity, Inequality and Covid-19 Emergency Remote Teaching and Learning. Postdigital Science and Education, 2, 946-967 https://doi.org/10.1007/s42438-020-00187-4

Davis, N. (2016). What Is the Fourth Industrial Revolution? World Economic Forum: Geneva, Switzerland. Retrieved October 20, 2020 from https://www.weforum.org/agenda/2016/01/what-is-the-fourthindustrial-revolution/

Dube, B. (2020). Rural Online Learning in the Context of COVID-19 in South Africa: Evoking an Inclusive Education Approach. Multidisciplinary Journal of Educational Research, 10(2), 135157. doi:10.4471/remie.2020.5607

Duffy, K., \& Ney, J. (2015). Exploring the Divides Among Students, Educators, and Practitioners in the Use of Digital Media as a Pedagogical Tool. Journal of Marketing Education, 37(2), 104-113.

Dwivedi, Y. K., Hughes, D. L., Coombs, C., Constantiou, I., Duan, Y., Edwards, J. S., Gupta, B, Lal, B., Misra, S., Prashant, P., Raman, R., Rana, N.P., Sharma, S.K., \& Upadhyay, N. (2020). Impact of COVID-19 pandemic on information management research and practice: Transforming education, work and life. International Journal of Information Management, 102211. https://doi. org/10.1016/j.ijinfomgt.2020.102211 
Gillett-Swan, J. (2017). The Challenges of Online Learning: Supporting and Engaging the Isolated Learner. Journal of Learning Design, 10(1), 20-30.

Gloria, A.M., \& Uttal, L. (2020). Conceptual Considerations in Moving from Face-to-Face to Online Teaching. International Journal on E-Learning, 19(2),139-159.

Guri-Rosenblit, S. (2009). Challenges facing distance education in the 21st century. In U. Bernath, A. Szucs, A. Tait, \& M. Vidal (Eds.), Distance and e-learning in transition: Learning innovation, technology and social challenges (pp. 5-22). London, UK: ISTE Ltd.

Hasan, N., \& Bao, Y. (2020). Impact of "e-Learning crack-up" perception on psychological distress among college students during COVID-19 pandemic: A mediating role of "fear of academic year loss". Children and Youth Services Review, 118, 1-9.

Hidalgo, A., Gabaly, S., Morales-Alonso, G., \& Urueña, A. (2020). The digital divide in light of sustainable development: An approach through advanced machine learning techniques. Technological Forecasting \& Social Change, 150(C),1-7. https://doi.org/10.1016/j.techfore.2019.119754

Hodges, C.B., Moore, S., Lockee, B.B., Trust, T., \& Bond, M.A. (2020). The Difference Between Emergency Remote Teaching and Online Learning. Retrieved January 27, 2020 from https://er.educause.edu/ articles/2020/3/the-difference-between-emergency-remote-teaching-and-online-learning

Kajee, L., \& Balfour, R. (2011). Students' access to digital literacy at a South African university: Privilege and marginalisation. Southern African Linguistics and Applied Language Studies, 29(2), 185-194.

Kebritchi, M., Lipschuetz, A., \& Santiague, L. (2017). Issues and Challenges for Teaching Successful Online Courses in Higher Education: A Literature Review. Journal of Educational Technology Systems, 46(1), 4-29.

Lee, K. (2017). Rethinking the accessibility of online higher education: A historical review. The Internet and Higher Education, 33(1), 15-23. DOI: 10.1016/j.iheduc.2017.01

Lombana-Bermudez, A., Cortesi, S., Fieseler, C., Gasser, U., Hasse, A., Newlands, G., \& Wu, S. (2020). Youth and the digital economy: Exploring youth practices, motivations, skills, pathways, and value creation. Youth and Media, Berkman Klein Center for Internet \& Society. Retrieved October 28, 2020 from https://cyber.harvard.edu/publication/2020/youth-and-digital-economy.

Martínez-Bravo, M-C., Sadaba-Chalezquer, C., \& Serrano-Puche, J. (2020). Fifty years of digital literacy studies: A meta-research for interdisciplinary and conceptual convergence. Profesional de la información, 29 (4), 1-16, e290428. https://doi.org/10.3145/epi.2020.jul.28

Mhlanga, D., \& Moloi, T. (2020). COVID-19 and the Digital Transformation of Education: What Are We Learning on 4IR in South Africa? Education Science, 10 (180), 1-11.

Mosca, J.B., Curtis, K.P., \& Savoth, P.G. (2019). New approaches to learning for generation Z. Journal of Business Diversity, 19(3), 66-74. doi:10.33423/jbd.v19i3.2214

Mpungose, C.B. (2020). Emergent transition from face-to-face to online learning in a South African University in the context of the Coronavirus pandemic. Humanities and social sciences communications, 7(113), 1-9.

Mzangwa, S. T. (2019). The effects of higher education policy on transformation in post-apartheid South Africa, Cogent Education, 6(1), 1592737.

Odit-Dookhan, K. (2018). Attitude towards e-learning: The case of mauritian students in public teis. PEOPLE International Journal Social Science, 4, 628-643.

Oke, A., \& Fernandes, F.A.P. (2020). Innovations in Teaching and Learning: Exploring the Perceptions of the Education Sector on the 4th Industrial Revolution (4IR). Journal of Open Innovation, 68 (2), 31-54.

Outhwaite, L. (2020). Inequalities in Resources in the Home Learning Environment (No. 2). Centre for Education Policyand Equalising Opportunities. London, UK: UCL Institute of Education. 
Owusu-Fordjour, C., Koomson, C.K., \& Hanson, D. (2020). The impact of Covid-19 on learning-the perspective of the Ghanaian student. European Journal of Education Studies, 7 (3), 88-101. doi: http://dx.doi.org/10.46827/ejes.v0i0.3000.

Palvia, S., Aeron, P., Gupta, P., Mahapatra, D., Parida, R., Rosnera, R., \& Sindhi, S. (2018). Online Education: Worldwide Status, Challenges, Trends, and Implications. Journal of Global Information Technology Management, 21(4),233-241. https://doi.org/10.1080/1097198X.2018.1542262

Priyadarshini, A., \& Bhaumik, R. (2020). E-readiness of Senior School Learners to Online Learning Transition amid COVID-19 Lockdown. Asian Journal of Distance Education, 15(1), 244-256. Retrieved from http://asianjde.org/ojs/index.php/AsianJDE/article/view/456

Radha, R., Mahalakshmi, K., Kumar, V.S., \& Saravanakumar, A.R. (2020). E-Learning during Lockdown of Covid-19 Pandemic: A Global Perspective. International Journal of Control and Automation, 13(4),1088-1099.

Ramsetty, A., \& Adams, C. (2020). Impact of the digital divide in the age of COVID-19. Journal of the American Medical Informatics Association, 27(7), 1147-1148.

Reedy, K., \& Parker, J. (eds.) (2018). Digital Literacy Unpacked. London: Facet Publishing. (pp. 63-82)

Reilly, J., Gallagher-Lepak S., \& Killion, C. (2017). E-learning in higher education: The digital divide and culture. Journal of Current Issues in Media and Telecommunications, 9(1), 1-14.

Soomro, K.A., Kale, U., Curtis, R., Akcaoglu, M., \& Bernstein, M. (2020). Digital divide among higher education faculty. International Journal of Educational Technology in Higher Education, 17(21), 1-16.

Takalani, T. (2008). Barriers to e-learning amongst postgraduate Black students in higher education in South Africa. Masters dissertation, Stellenbosch University.

Takavarasha, S., Cilliers, L., \& Chinyamurindi, W., (2018). 'Navigating the unbeaten track from digital literacy to digital citizenship: A case of university students in South Africa's Eastern Cape province'. Reading \& Writing, 9(1), 1-15. a187. https://doi.org/ 10.4102/rw.v9i1.187

Williamson, B., Eynon, R., \& Potter, J. (2020). Pandemic politics, pedagogies and practices: Digital technologies and distance education during the coronavirus emergency. Learning, Media and Technology, 45(2), 107-114. https://doi.org/10.1080/17439884.2020.1761641.

Worley, W.L., \& Tesdell, L.S. (2009). Instructor time and effort in online and face-to-face teaching: Lessons learned. IEEE Transactions on Professional Communication, 52(2), 138.

Yen, T.-F. T. (2020). The performance of online teaching for flipped classroom based on COVID-19 aspect. Asian Journal of Education and Social Studies, 8(3), 57-64.

Yu, E., \& Canton, S. (2020). Student-inspired optimal design of online learning for generation Z. Journal of Educators Online, 17(1), 1-11.

Zhou, L., Wu, S., Zhou, M., \& Li, F. (2020). 'School's Out, But Class' On', The Largest Online Education in the World Today: Taking China's Practical Exploration During The COVID-19 Epidemic Prevention and Control as an Example. Best Evidence Chinese Education, 4(2), 501-519. DOI https://doi.org/10.15354/bece.20.ar023. 